\begin{tabular}{|l|l|}
\hline Postprint Version & 1.0 \\
\hline Journal website & $\underline{\mathrm{http}: / / w w w 3 . i n t e r s c i e n c e . w i l e y . c o m / j o u r n a l / 122546648 / \text { abstract }}$ \\
\hline Pubmed link & $\underline{\mathrm{http}: / / \mathrm{www} \text {.ncbi.nlm.nih.gov/pubmed/19682126 }}$ \\
\hline DOI & $10.1111 / \mathrm{j} .1532-5415.2009 .02440 . \mathrm{x}$ \\
\hline
\end{tabular}

This is a NIVEL certified Post Print, more info at http://www.nivel.eu

\title{
The Use of Physical Restraints in Home Care in the Netherlands
}

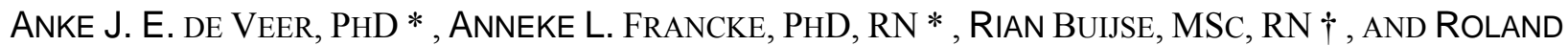 \\ D. FRIELE, PHD * \\ From the *Netherlands Institute for Health Services Research, Utrecht, the Netherlands; \\ †Netherlands Centre for Excellence in Nursing, Utrecht, the Netherlands; and ¥Tranzo, Tilburg University, \\ Tilburg, the Netherlands. \\ Address correspondence to Anke J. E. de Veer, NIVEL, Netherlands Institute for Health Services \\ Research, PO Box 1568, 3500 BN Utrecht, the Netherlands. E-mail: a.deveer@nivel.nl
}

\begin{abstract}
OBJECTIVES: To gain more knowledge of the application of physical restraints to restrict, restrain, or prevent movement by elderly people living at home.
\end{abstract}

DESIGN: Survey.

SETTING: Nursing staff in Dutch home care.

PARTICIPANTS: One hundred fifty-seven nursing staff in home care (registered nurses and certified nursing assistants) from a randomly selected and nationally representative panel returned the questionnaire (response rate $72 \%$ ).

MEASUREMENTS: A structured questionnaire on the use of physical restraints.

RESULTS: Four of every five nursing staff members have applied physical restraints. The use of bed rails, putting the client in a deep chair or using a chair with a table, and locking doors to prevent wandering were most frequently applied, often at the request of the client or his or her family. Protection of the client is the reason most frequently given for these actions. Almost all respondents (94\%) know of no alternatives, nor does consensus exist on what is considered to be a physical restraint.

CONCLUSION: Guidelines are necessary regarding the course of action to be taken when a client is in danger of hurting him- or herself. Further education on and due consideration of the use of physical restraints in home care are also required.

Physical restraints are measures used to restrict, restrain, or prevent movement of a patient. Nurses continue to apply physical restraints in nursing homes and hospitals, ${ }^{1-4}$ with prevalences ranging from $41 \%$ to $64 \%$ in nursing homes and $33 \%$ to $68 \%$ in hospitals having been reported. ${ }^{5}$ In Dutch psychogeriatric nursing homes, physical restraints were applied to $56 \%$ of residents. The administration of psychoactive medication is also common, with $65 \%$ of nursing home patients with dementia being given psychoactive medication. ${ }^{6}$ Individuals who often show physically aggressive or self-injurious behavior or have more severely impaired mobility and poorer cognitive status are found to have a higher chance of being physically restrained. $5,7,8$

Before this study, the use of physical restraints in home care had not been thoroughly investigated, but there were indications that restraints were being applied in home care. ${ }^{5,9,10}$ In this study, nursing staff members working in home care were asked about the use of physical restraints. 


\section{Veer, A.J.E. de, Francke, A.L., Buijse, R., Friele, R.D. The use of physical restraints in home care in the Netherlands. Journal of the American Geriatrics Society: 2009}

\section{Effects of Restraint Use}

The use of physical restraints has not been proven to be effective, and some researchers have shown it to be associated with greater risk of injuries such as pressure ulcers, aspiration and breathing difficulties, and falls and fall-related injuries and even death. ${ }^{1,11-13}$

A recently published review of the available U.S. literature on risks and benefits associated with restraints for wheelchair users showed weak evidence physical restraints causing a considerable number of deaths from asphyxia. The figures included deaths that occurred at home, with most deaths happening while people were restrained in wheelchairs or in bed..$^{14}$ Other adverse effects have also been reported, such as depression, aggression, and general feelings of discomfort, for instance, absence of privacy, freedom, and independence, ${ }^{5}$ as well as deterioration in social behavior. ${ }^{11,12}$ Even the use of side rails has not been proven to decrease fall occurrence. ${ }^{15}$

\section{Elderly People in Need of Care and Support}

Approximately $12 \%$ of elderly people (aged $\geq 55$ ) living at home experience serious or moderate disabilities combined with mental problems or incontinence. Approximately $65 \%$ of them live alone ${ }^{16}$ and are at risk of falling or dangerous behavior, such as not turning off the gas burner or wandering outside and getting lost. The vast majority of older people living at home want to remain there for as long as possible, ${ }^{17}$ and much of the policy pursued in recent decades has reflected this aspiration. High value placed on personal autonomy and the desire of older adults to stay in their own environment for as long as is feasible is reflected in the establishment of domiciliary services such as meals on wheels and domestic care.

\section{Home Care}

If older adults become frailer, they can receive care and support from nursing assistants or nurses from a home care organization. Dutch professional home care constitutes care supporting activities of daily living (i.e., physical or personal care), technical nursing care, and psychosocial care - all delivered by nursing staff. Professional home care can be episodic after a hospital stay but is more often longer lasting. Home care is given primarily to older adults, with $86 \%$ of the care delivered to people aged 65 and older and $53 \%$ of the care is to people aged 80 and older. ${ }^{18,19}$ There are indications that Dutch nursing staff apply physical restraints in home care; whether such care meets the standards of autonomy and quality for care is debatable. Older adults should, then, be protected from the use of physical restraints. More knowledge about the application of physical restraints is useful for promoting proper professional training and general policy, including appropriate rules to protect elderly patients.

\section{Research Questions}

The objective of this research was to answer the following questions.

How often do nursing staff members apply physical restraints to clients still living in their own homes? Why do nursing staff members apply physical restraints to clients still living in their own homes? How are physical restraints applied (who decides, who supervises, and how is the decision recorded)? Do guidelines exist for applying physical restraints at home?

\section{METHODS}

\section{Subjects}

The study population consisted of home care nursing staff members from a nationally representative research sample referred to as the Nursing Staff Panel. Candidates for the Nursing Staff Panel were recruited from a random sample of nursing staff registered with the Dutch Employee Insurance Agency. This agency has addresses of all employees in health care and their job titles. The agency asked a random sample of nursing staff to participate in the panel and complete a postal questionnaire twice a year. From the group of employees who were willing to participate, the panel coordinator (AdV) selected 219 persons working in home care to form the Nursing Staff Panel. Selection has been made in such a way that the age and sex of the selected group correspond to the age and sex of the population of Dutch home care nursing staff.

The panel consists of certified nursing assistants (CNAs) and registered nurses (RNs). The education of Dutch CNAs consists of 3 years of vocational training after secondary education, which is different from the situation in most other countries, like the United States, where CNAs often have vocational training of less than 1 year. Dutch RNs have at least 4 years of vocational training at an associate degree or bachelor's level. 


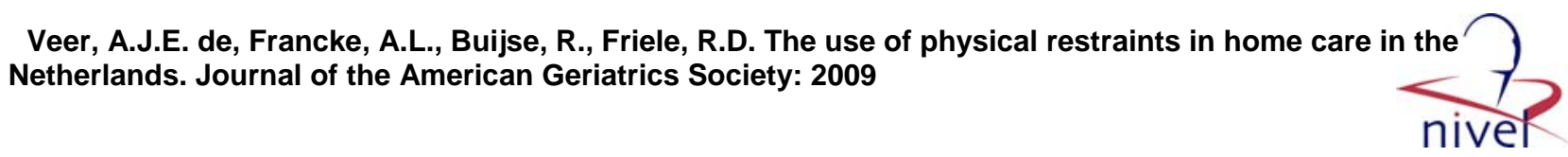

In January 2005, 157 respondents (70 CNAs and 87 RNs) completed a postal questionnaire about restraint use (response rate 71.7$)$. Nearly all respondents $(94.9 \%$ ) worked exclusively with clients; $5.1 \%$ were also involved in management tasks. The respondents worked an average \pm standard deviation of $22.2 \pm 9.8$ hours per week and had been working in care for an average of $18.1 \pm 8.9$ years. The average age of almost 45.7 \pm 9.2 was slightly higher than the sampling frame of nursing staff registered with the Employee Insurance Agency.

\section{Questionnaire}

The questionnaire consisted of prestructured, forced-choice items. A questionnaire used in an explorative Dutch research on restraint use in community care for people with dementia or intellectual disability was adapted. ${ }^{9}$ These questions were used in earlier research and were found to be valid. ${ }^{9}$ The original questionnaire was based on a review of the literature and 108 interviews in 35 healthcare organizations and was the basis for the questions on restraint use (research questions 1-3). The following questions were asked: How often do you apply a restraint? What are the reasons for applying the restraint? Who decides to apply the restraint? Whose permission has been obtained? Who supervises during the time a patient is restrained? How does this supervision take place? How is the restraint use recorded?

The questionnaire started with a definition of physical restraints as measures used by nursing staff to keep a patient away from a (potentially) dangerous situation. Subsequently, a number of measures were described. Six physical restraints were described: fixation by means of devices including belts, special sheets, and wrist straps; isolation (putting a client in a special room); bed rails; restraining freedom of movement using a deep chair or a chair with a table; locking the client's room or home to protect the client from leaving; and seclusion (putting a client in a separate room without locking the door). The aforementioned questions were asked concerning each restraint separately. Whether guidelines on restraints exist within the organization, whether nursing staff has a duty to make a note of the application of a physical restraint, and whether nursing staff regularly (e.g., annually) receives a report of these records was also asked. Finally whether the respondent had ideas how to reduce restraint use (yes or no) was asked.

Nine experts in the field of restraint use individually assessed the face validity and content validity of the draft questionnaire; these experts were four persons with a nursing background, three researchers in this field, and two representatives of the Ministry of Health. Two of them were also legal experts specializing in the use of physical restraints and compulsory treatment in health care. They were asked to comment individually on the face validity and content validity of the questionnaire and to judge whether the questions and possible answers were unequivocal. This resulted in minor adaptations to the questionnaire.

\section{Analyses}

The analyses were performed using the statistical program SPSS (version 11.5, SPSS, Inc., Chicago, IL). First, all analyses were conducted within the subgroups of 70 CNAs and 87 RNs. Differences between the two groups were analyzed using chi-square tests and Fisher exact tests. There was no evidence of any between-group differences in perceptions or experiences concerning physical restraints at $\mathrm{P}=.05$, only the results of the total group are presented.

\section{RESULTS}

\section{The Use of Physical Restraints in Home Care}

Bed rails are the most commonly applied restraint in home care, with $71.8 \%$ of the nursing staff having used bed rails at some time. They also lock (front) doors to protect the client from leaving $(37.7 \%)$ and prevent their clients from leaving their chairs $(18.1 \%)$. Nursing staff members rarely use other physical restraints, such as fixation aids - belts tied or special sheets $(1.9 \%)$.

Table 1 shows how often nursing staff members in home care use physical restraints. The use of bed rails and locking a door occur most frequently; every week, $35.3 \%$ of the nursing staff members use bed rails, and $18.8 \%$ lock the doors of clients who live at home.

\section{[TABLE 1]}

\section{Reasons for Applying Physical Restraints}

Respondents who apply physical restraints were asked what their main reasons were for doing so. The reasons most frequently given were protection of the client and adherence to the request of the client or his or her representative (Table 2). 


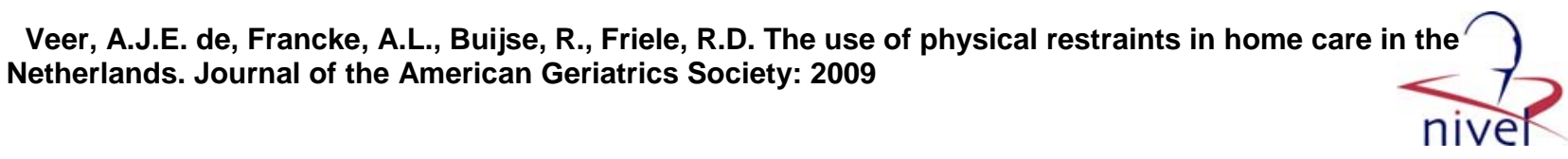

\section{[TABLE 2]}

Most respondents (93.6\%) indicated that they know of no alternatives to these measures that restrict clients' freedom. Nursing staff's opinions differed on whether certain restraints could be considered restriction of freedom. Locking the door to protect the client from leaving was most frequently regarded as restriction of freedom $(65.1 \%) ; 57.9 \%$ of the nursing staff considered using bed rails to be a restriction of freedom, whereas limiting freedom of movement by putting someone in a chair was less frequently regarded as such $(39.7 \%)$.

\section{The Application of Physical Restraints}

A family member or informal caregiver most often made the decision to use a physical restraint, followed by the nursing staff member (Table 3). General practitioners are hardly ever involved in this decision. The respondents also used the category "other," indicating that the client made the decision himself or herself. Although the nursing staff and a family member or informal carer mostly made the decision, the client was nearly always asked explicitly for permission.

\section{[TABLE 3]}

Respondents indicated that monitoring the client was mainly their task or that of the family member or informal carer. One-third of respondents indicated that no specific attention was paid to who should monitor the client, which means that it was not clear who was responsible for monitoring. Many nursing staff members indicate that there was no monitoring at all during the use of physical restraints, and half of the nursing staff (52.5\%) stated that no one was charged with supervision in the particular case of locking the (front) door to prevent the client from leaving.

A large number of the respondents used the "other" category, and most of them mentioned in their comments that monitoring depended on the presence of family members and informal caregivers or took place at times when care was being provided.

Nearly all of the nursing staff members noted restraint use in the client's care file (Table 3 ).

\section{Guidelines}

Nearly all respondents indicated that there were no guidelines within their organizations on the use of physical restraints. Existing guidelines most frequently concerned restraining people with devices such as belts, and $12.1 \%$ of the nursing staff reported having a guideline addressing this subject.

Furthermore, hardly any guidelines existed on documenting the use of physical restraints, and only $19.0 \%$ were aware of whether any such guidelines existed. The remaining $65.4 \%$ knew nothing of such guidelines, and $15.6 \%$ knew that such guidelines did not exist within their own organizations. Six percent (5.9\%) occasionally received reports on the physical restraints applied by nursing staff, but three-quarters never received a report of this kind, and the remaining $19.0 \%$ did not know whether they received such reports.

\section{CONCLUSION AND DISCUSSION}

The following emerges from this study.

- Four of every five nursing staff members in home care have physically restrained a person at some time. The methods most often used are bed rails, preventing clients from leaving their chairs, and locking (front). This confirms earlier observations that physical restraints are applied in home care. $^{5}$

- Physical restraints are most often applied for the safety of the client. Staff in residential settings also frequently consider restraint use as being necessary to safeguard the patient from physical harm. ${ }^{5,20}$

- Restraint use in home care was usually found to happen at the request of the client or of his or her family. Most nursing staff members (93.6\%) knew of no other options apart from the application of the restraints requested. Another study supports this finding that nursing staff experiences restraints as the most expedient option available. ${ }^{4}$

- Nursing staff members do not always consider the actions to be physical restraints. This was found not only in another Dutch study that indicated differing opinions between professionals on what constitutes a restraint, ${ }^{9}$ but also in studies in other countries, where there was found to be a lack of consensus on what constitutes a restraint. ${ }^{21}$ 


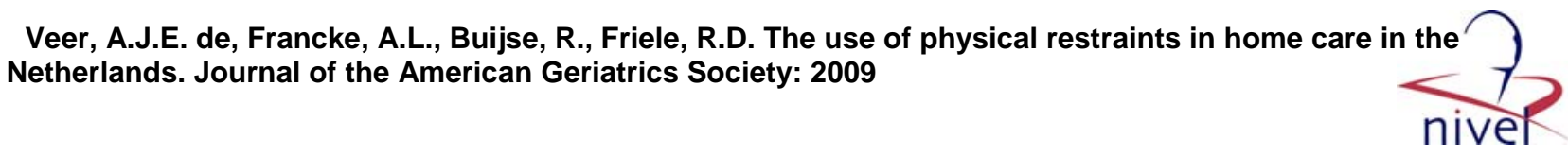

- Family members or nursing staff, not general practitioners, most often make the decision to use physical restraints. One study also found that family members have a significant influence on restraint use (e.g., when a client returned from a hospital where side rails were used, family members insisted on side rails being used). ${ }^{20}$

- Approximately one-third of the nursing staff members indicated that no attention was paid to the monitoring of the restrained client. Most nursing staff members made a note in the care file when applying a physical restraint. Guidelines on restraint use in home care organizations were scarce.

\section{Limitations of the Study}

This study has some limitations. First, this study was based on self-reported use of physical restraints. Nursing staff may be reluctant to admit the use of such restraints, and the percentages reported may, therefore, constitute an under-representation of actual use. Consequently, more research is required.

Second, it was found that the majority of the nursing staff members reportedly lock doors at the request of the client or the client's family. Although the respondents received extensive information about the aim of the questionnaire, and the majority (65.1\%) regarded locking the front door as a physical restraint, it cannot be excluded that some of them interpreted this measure as locking the outer door of the house or apartment to keep strangers out. Third, the data do not allow the number of clients subjected to physical restraints to be estimated, because this requires a study at the individual patient level, although the research shows that most home care nursing staff has to address situations in which physical restraints are used. Many people want to live at home for as long as possible, and these results show the resulting urgency in examining the phenomenon of the use of physical restraints.

\section{Practical Implications of This Study}

Making decisions on the use of restraints is found to be related to the individual nursing staff member and is ambiguous as a consequence. ${ }^{5,7,22}$ Guidelines on the course of action to be taken if a nursing staff member considers physical restraint to be necessary and further education are required.

Healthcare organizations (such as home care, nursing care, hospitals), acting jointly with the Netherlands Ministry of Health, the Netherlands Health Care Inspectorate, and the sector organization representing the healthcare insurance providers, issued a policy statement in 2006 about the use of restraints at home. ${ }^{23}$ The principal issue addressed in this statement is that restraint use is allowed in home care subject to specific conditions. A nursing staff member must consult the patient (or a family member when the patient is not able to make decisions), and the physician makes the decision after considering the possibilities to meet the elderly person's needs and assure his or her safety. In the case of a client who is no longer able to make decisions about his or her own situation and who offers resistance to the use of restraints, the nursing staff must consider whether a a needs assessment should be applied for with a view to admission to a residential setting where restraint use is allowed subject to strict conditions.

In view of the outcomes of the study described in this article, it is important that all home care organizations should implement the policy statement about the use of restraints in home care. This means, among other things, that they must develop educational programs for nursing staff members and physicians; mere distribution of the statement is not enough. Professionals, both nursing staff members and physicians, need to know how to assure safety and surveillance and how to find solutions when family members have different opinions. They also need to know how to interpret clients' behavior. Can the client make proper decisions? How do you define "resistance"? When does a client offer resistance against a restraint? Furthermore, nursing staff members need to know where and how to report on the (non)use of restraints.

Education should include more knowledge about what physical restraints are, the consequences of restraint use, and the range of possibilities for meeting elderly people's needs, including needs for safety. The presumed relationship between safety and restraint use means that nursing education must focus on determining risk factors for injury and on how to create a safe environment. This study shows that nursing staff lacks knowledge on how to meet elderly people's needs, and research has demonstrated a reduction in the use of physical restraints when advanced practice nurses are employed ${ }^{24}$-nurses who provide a wide range of practical, educational, and consultative services. The use of technology such as video monitoring, alarm systems, sensor mats, and infrared systems can help to ensure safety and surveillance in the homes of elderly people, although these technologies could also be regarded as restraints because they limit the privacy of the individual. ${ }^{7}$ Other recommendations to facilitate minimal restraint use imply continuous communication with the client and the family, because the latter is found to play a major role in asking for restraints. Studies in residential settings like nursing homes show that carefully implemented, multifaceted 


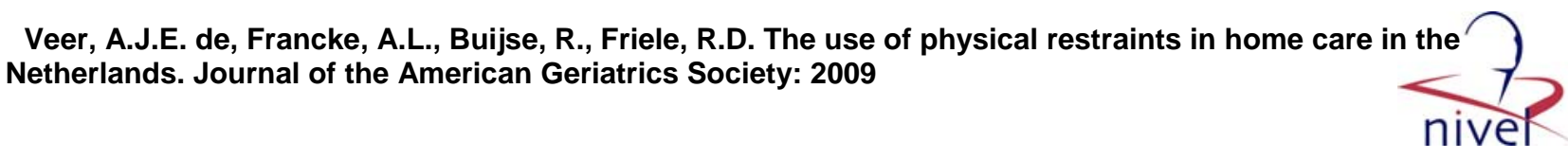

interventions can successfully reduce the number of physical restraints concurrent with a stable fall rate. ${ }^{25,26}$ A review study shows that there are successful prevention strategies for people living in their own homes. ${ }^{27}$ These interventions should include a multidisciplinary screening of risk factors in the health of a person as well as in his or her environment, and examples of interventions found to be effective are muscle strengthening and balance retraining, alterations to clients' homes, and withdrawal of psychotropic medication.

\section{ACKNOWLEDGMENTS}

Conflict of Interest: The editor in chief has reviewed the conflict of interest checklist provided by the authors and has determined that the authors have no financial or any other kind of personal conflicts with this paper. This research was financed by the Netherlands Centre for Excellence in Nursing and the Dutch Association of Nurses.

Author Contributions: Anke de Veer and Anneke Francke served as principal investigators and were responsible for study concept and design, analysis, interpretation of data, and preparation of the manuscript. Rian Buijse was involved in the preparation of the questionnaire and preparation of the manuscript. Roland Friele contributed to the study concept and design and preparation of the manuscript.

Sponsor's Role: The sponsors of this research had an advisory role, giving suggestions about the subjects who were part of the questionnaire. They have no interests in whatever directions the results are pointing in. The opinions expressed in this article are those of the authors.

\section{REFERENCES}

1.Demir A. Nurses' use of physical restraints in four Turkish hospitals. J Nurs Scholarship 2007;39:38-45.

2.Evans $\mathrm{LK}$, Strumpf NE, Allen-Taylor $\mathrm{L}$ et al. A clinical trial to reduce restraints in nursing homes. J Am Geriatr Soc 1997;45:675-681.

3.Hamers JP, Gulpers MJ, Strik W. Use of physical restraints with cognitively impaired nursing home residents. J Adv Nurs 2004;45:246-251.

4.Nay R, Koch S. Overcoming restraint use. J Gerontol Nurs 2006;32:433-438.

5.Hamers JPH, Huizing AR. Why do we use physical restraints in the elderly? Z Gerontol Geriatr 2005;38:19-25.

6.Zuidema SU, Derksen E, Verhey FRJ et al. Prevalence of neuropsychiatric symptoms in a large sample of Dutch nursing home patients with dementia. In J Geriatr Psychiatry 2007;22:632638.

7.Huizing AR, Hamers JPH, de Jonge $\mathrm{J}$ et al. Organisational determinants of the use of physical restraints: A multilevel approach. Soc Sci Med 2007;65:924-933.

8.Zuidema SU, Koopmans RTCM, Verhey FRJ. Prevalence and predictors of neuropsychiatric symptoms in cognitively impaired nursing home patients. J Geriatr Psychiatry Neurol 2007;20:4149.

9.Arends LAP. Beperkt door zorg. Toepassing van vrijheidsbeperkingen op psychogeriatrische patiënten en verstandelijk gehandicapten op plaatsen waar de Wet Bopz niet van toepassing is. [Restrained by care. Application of restrictions to the freedom of psychogeriatric patients and the mentally handicapped at locations where the BOPZ (Netherlands Psychiatric Hospitals (Compulsory Admissions) Act) does not apply]. The Hague, Netherlands Ministry of Health, Welfare and Sports, 2004.

10.Bakker RH, Tiesinga LJ, Gassman P et al. Vrijheidsbeperkende maatregelen in niet BOPZ aangemerkte instellingen. Gelegaliseerde dwang of gedwongen legalisering? [Measures that restrict freedom in institutions not registered under the terms of the BOPZ (Netherlands Psychiatric Hospitals (Compulsory Admissions) Act). Legalized compulsion or compulsory legalization?] TSG 2002; 80(7): 455-462.

11.Evans D, Wood J, Lambert L et al. Physical restraint in acute and residential care: $A$ systematic review. In: Adelaide S., editor. Australia, Australia: Joanna Briggs Institute for Evidence Based Nursing and Midwifery, 2002, pp 1-134. 
Veer, A.J.E. de, Francke, A.L., Buijse, R., Friele, R.D. The use of physical restraints in home care in the Netherlands. Journal of the American Geriatrics Society: 2009

12.Evans D, Wood J, Lambert L. Patient injury and physical restraint devices: A systematic review. J Adv Nurs 2003;41:274-282.

13.Neufeld RR, Libow LS, Foley WJ et al. Restraint reduction reduces serious injuries among nursing home residents. J Am Geriatr Soc 1999;47:1202-1207.

14.Chaves ES, Cooper RA, Collins DM et al. Review of the use of physical restraints and lap belts with wheelchair users. Assist Technol 2007;19:94-107.

15.Capezuti E, Wagner LM, Brush B et al. Consequences of an intervention to reduce restrictive side rail use in nursing homes. J Am Geriatr Soc 2007;55:344-3341.

16.Ministry of Health. Brancherapporten [Sector reports]. The Hague: Ministry of Health, 2005.

17.Kullberg J. Ouderen van nu en van de toekomst. Hun financiële spankracht, zorgbehoefte en woonwensen [Elderly people today and in the future. Their financial resilience, care needs and residential requirements]. The Hague: SCP, 2005.

18.CBS [Statistics Netherlands]. Thuiszorg 2005: minder cliënten, meer uren zorg [Home care 2005: fewer clients, more hours of care] [on-line] Available at http://www.cbs.nl Accessed February 13, 2008.

19.van der Kwartel A, Paardekooper P, vanderVelde F et al. Arbeid in zorg en welzijn [Working in care and welfare]. Utrecht: Prismant, 2007.

20. Moore K, Haralambous B. Barriers to reducing the use of restraints in residential elder care facilities. $\mathrm{J}$ Adv Nurs 2007;58:532-540.

21.Koch S. Restraining nursing home residents. Aust J Adv Nurs 1994;11:9-14

22.Pekkarinen L, Elovainio M, Sinervo T et al. Nursing working conditions in relation to restraint practices in long-term care units. Med Care 2006;44:1114-1120.

23.Normen voor Verantwoorde zorg Thuis [Standards for reliable care at home]. Utrecht: Arcares Z-org, AVVV, LOC, NVVA, Sting, 2006.

24.Wagner LM, Capezuti E, Brush B et al. Description of an advanced practice nursing consultative model to reduce restrictive siderail use in nursing homes. Res Nurs Health 2007;30:131-140.

25Oliver D, Connelly JB, Victor CR et al. Strategies to prevent falls and fractures in hospitals and care homes and effect of cognitive impairment: Systematic review and meta-analyses. BMJ 2006;334:82.

26. Rask K, Parmelee PA, Taylor JA et al. Implementation and evaluation of a nursing home fall management program. J Am Geriatr Soc 2007;55:342-349.

27.Gillespie LD, Gillespie WJ, Robertson MC et al. Interventions for preventing falls in elderly people. Cochrane Database Syst Rev. 2003 CD000340.

\section{TABLES}

\begin{tabular}{lccc}
\hline Table 1. The Use of Three Physical Restraints Most Commonly Applied in Home Care $(\mathbf{n}=157)$ \\
\cline { 2 - 4 } & \multicolumn{3}{c}{$\%$} \\
\cline { 2 - 4 } Reported Frequency & Bed Rails & $\begin{array}{c}\text { Use of a Deep Chair or a Geriatric } \\
\text { Chair with Table or Putting a Table } \\
\text { in Front of the Chair }\end{array}$ & $\begin{array}{c}\text { Locking Client's } \\
\text { Room or Home }\end{array}$ \\
\hline$\geq 1$ time per week & 35.3 & 7.1 & 18.8 \\
$1-3$ times per month & 10.3 & 1.9 & 6.5 \\
Approximately 1-5 times every 6 months & 12.2 & 3.9 & 5.2 \\
$\leq 1$ time per year & 14.1 & 5.2 & 7.1 \\
Never & 28.2 & 81.9 & 62.3 \\
\hline
\end{tabular}


Veer, A.J.E. de, Francke, A.L., Buijse, R., Friele, R.D. The use of physical restraints in home care in the Netherlands. Journal of the American Geriatrics Society: 2009

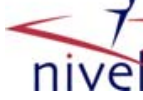

Table 2. Reasons for Use of Measures that Restrict Freedom, Classified According to Type of Restraint (Several Answers Possible)

\begin{tabular}{|c|c|c|c|}
\hline \multirow[b]{2}{*}{ Reason } & \multicolumn{3}{|c|}{$\%$} \\
\hline & Bed Rails $(n=112)$ & $\begin{array}{l}\text { Use of a Deep Chair or a Geriatric } \\
\text { Chair with Table or Putting a Table } \\
\text { in Front of the Chair }(n=28)\end{array}$ & $\begin{array}{l}\text { Locking Client's Room } \\
\text { or Home }(n=59)\end{array}$ \\
\hline Client's protection & 83.0 & 85.7 & 61.0 \\
\hline Client's request & 55.4 & 42.9 & 59.3 \\
\hline Request of client's representative & 40.2 & 42.9 & 61.0 \\
\hline Little time for supervision & 4.5 & 14.3 & 6.8 \\
\hline Little time for diverting activities & 0.9 & 10.7 & - \\
\hline Without this measure, client will not be easy to handle & - & 3.6 & 3.4 \\
\hline Preventing danger to others & 0.9 & - & 3.4 \\
\hline \multirow[b]{2}{*}{ Decision-Making Process } & \multicolumn{3}{|c|}{$\%$} \\
\hline & Bed Rails $(n=112)$ & $\begin{array}{l}\text { Use of a Deep Chair or a Geriatric } \\
\text { Chair with Table or Putting a Table } \\
\text { in Front of the Chair }(n=28)\end{array}$ & $\begin{array}{c}\text { Locking Client's } \\
\text { Room or Home }(n=59)\end{array}$ \\
\hline \multicolumn{4}{|l|}{ Who decides? (several answers possible) } \\
\hline Family member or informal carer & 68.8 & 71.4 & 79.7 \\
\hline Nursing staff & 57.1 & 57.1 & 39.0 \\
\hline Supervising nurse & 19.6 & 21.4 & 15.3 \\
\hline General practitioner & 14.3 & 14.3 & 5.1 \\
\hline Psychologist, psychiatrist & 0.9 & 7.1 & 1.7 \\
\hline Other & 25.0 & 17.9 & 32.2 \\
\hline \multicolumn{4}{|l|}{ Whose permission is asked? (several answers possible) } \\
\hline Client & 16.1 & 14.3 & 18.6 \\
\hline Family member or informal carer & 1.8 & - & 15.3 \\
\hline Both client and family member & 78.6 & 82.1 & 59.3 \\
\hline No permission asked & 1.8 & 3.6 & 1.7 \\
\hline Other & 2.7 & 3.6 & 3.4 \\
\hline \multicolumn{4}{|l|}{ Who monitors the client? (several answers possible) } \\
\hline Nursing staff & 55.0 & 50.0 & 52.5 \\
\hline General practitioner & 1.8 & 3.6 & 3.4 \\
\hline Psychologist or psychiatrist & - & 3.6 & 1.7 \\
\hline Supervising nurse & 7.2 & 10.7 & 10.2 \\
\hline Family member or informal carer & 55.0 & 60.7 & 45.8 \\
\hline Other & 10.8 & 10.7 & 10.2 \\
\hline No specific attention for monitoring & 34.2 & 32.1 & 32.2 \\
\hline \multicolumn{4}{|l|}{ Type of monitoring (several answers possible) } \\
\hline No monitoring & 31.9 & 42.9 & 52.5 \\
\hline 24-hour monitoring & 30.1 & 25.0 & 11.9 \\
\hline Only during the day & 12.4 & 17.9 & 13.6 \\
\hline Only at night & 15.9 & 3.6 & 13.6 \\
\hline Other & 22.3 & 10.7 & 11.9 \\
\hline \multicolumn{4}{|l|}{ How recorded? (several answers possible) } \\
\hline Nowhere & 18.6 & 17.9 & 6.9 \\
\hline Care plan or care file & 83.2 & 85.7 & 91.4 \\
\hline Oral transfer to colleague & 24.8 & 32.1 & 31.0 \\
\hline Central registration within home care organization & 6.2 & 14.3 & 17.2 \\
\hline Other & 3.5 & 3.6 & 6.9 \\
\hline
\end{tabular}

Several answers were possible for each question. 